\title{
The Impact of Management Characteristics on Overseas M\&A Performance: A Comparative Analysis of Two Chinese Enterprises.
}

\author{
Yuyu Feng, Ph.D Candidate \\ Binary University of Management and Entrepreneurship \\ No 1, IOI Business Park P'Siaran Puchong Jaya \\ Selatan 4100 Selangor, Malaysia \\ Jules Harris Danarson, Ph.D \\ School of International Education Guangxi \\ University of Finance and Economics \\ 100 Mingxiu West Road, Nanning, \\ Guangxi, P.R. China
}

\begin{abstract}
With the continuous implementation of China's go-global strategy, overseas mergers and acquisitions (M\&A) are receiving more and more attention as an effective way for enterprises to quickly acquire overseas resources and enhance international competitiveness. This paper is a comparative case study of overseas M\&A of two Chinese companies, Sany Heavy Industry Co. Ltd. and Guangxi Liugong Machinery Co. Ltd., which measures the M\&A performance and studies the impact of management characteristics on overseas M\&A performance. The finding outlines the fact that the M\&A approaches adopted by the two companies are mainly focused on the pursuit of technological innovation, expansion of the international market and enhancement of brand competitiveness. By comparison, Sany is better than Liugong in pursuing technological innovation and expanding international market, and is more performant thanks to the unique characteristics of its management being run by younger staff members with Ph.D degrees, high-level engineering capabilities and international background.
\end{abstract}

Keywords: Overseas M\&A, Management characteristics, M\&A motivational factors, M\&A performance.

\section{Introduction}

Overseas mergers and acquisitions are one of the important ways for China to implement the "go-global" strategy. They are also an effective means for Chinese enterprises to actively integrate into the global value chain, participate in international competition and achieve leap-forward development of enterprises. Although Chinese companies have reduced their overseas acquisitions since 2017, they have remained active in the global M\&A market. The measurement and evaluation of overseas M\&A performance and the influencing factors of such business practice continue to be a burning issue in the practice settings and academic circles. This paper evaluates the M\&A performance based on the completion of the company's motivational factors for overseas M\&A, and further analyzes the impact of corporate management characteristics on overseas M\&A performance. The research is aimed at enriching the literature on the measurement and evaluation of overseas M\&A performance and its influencing factors, and providing as well as effectively guiding the improvement of overseas M\&A performance from the perspective of management structure optimization.

\section{Literature Review}

\subsection{Performance Evaluation of Overseas M\&A}

The mainstream methods of overseas M\&A performance measurement are divided into two: the excess return method and the accounting index method. In terms of the literature using the excess return method, a large number of studies have shown that the acquirer companies cannot obtain positive excess returns (Franks \& Harris, 1989; Jarrell, Gregg \& Poulsen, 1987; Yu Guang, Yang Rong, 2000; Zhang Xin, 2003) and a few scholars have found that the acquirer companies have positive excess returns (Dodde \& Rubac, 1977; Li Shanmin, Chen Yudi, 2002; Gu Lulu, Robert Reed, 2011). As regards the literature on the use of accounting index methods, a large number of studies have been conducted to measure and evaluate the performance of overseas M\&A using financial indicators that reflect corporate profitability, development capability, operating capability, and debt serviceability (Yan Daying, 2009; Feng Yinbo, Liu Yujia, 2016; Hu Haiqing, et al., 2016). 
Some scholars believe that the performance of mergers and acquisitions can be reflected by the satisfaction degree of M\&A motivation, which can be measured by selecting quantifiable indicators (Yang Xiaojia, Chen Shou, 2005; Zhou Shaoni, Wen Haitao, 2013; Yin Aizhen, etc., 2018).

\subsection{Motivational Factors for Overseas M\&A}

At an international level, traditional literature has summarized three main motivational factors for corporate foreign direct investment (FDI), including resource seeking, strategic-assets seeking, and market seeking (Liu et al., 2017). For a country of an emerging market, China's motivation for overseas mergers and acquisitions is mainly of strategic asset seeking and market seeking (Yuan Zeming et al., 2018). Specific technology seeking (GuoRui et al., 2012) and brand seeking (Wu Xianming, Su Zhiwen, 2014) belong to the category of strategic assets.

\subsection{The Influence of Management Characteristics on the Performance of Overseas M\&A}

Regarding the influencing factors of the performance of overseas mergers and acquisitions, most scholars pay attention to the macroeconomic factors such as institutional background and cultural differences of the M\&A parties, while there is less research on management of the M\&A parties as referred to the decision-makers and leaders of overseas M\&A. In the existing literature, management's M\&A experience and education background (Nadolska and Barkema, 2014) as well as overseas background (Wu Yingyu, Chen Song, 2017; Liu Bai, Liang Chao, 2017) are the main factors in improving the performance of overseas M\&A.

\subsection{Summary of Literature Review}

Research on the motivational factors for overseas M\&A is very rich and the views are unified within that scope. For the evaluation of the performance of overseas M\&A, on the one hand, due to some doubts about the effectiveness of China's capital market, scholars have disputed the rationality of using the excess income method to evaluate the performance of overseas mergers and acquisitions. On the other hand, most of the application of accounting index method uses financial indicators, and M\&A performance may not always be reflected by those financial indicators. Therefore, while considering the performance of M\&A as the degree of satisfaction of M\&A motivation, this article selects indicators that can quantify the degree of satisfaction of M\&A motivation to evaluate the performance of overseas M\&A and further analyze the influence of management characteristics on the performance of overseas M\&A. With this approach, the article enriches relevant literature on the performance evaluation of overseas M\&A and the influence of management characteristics on overseas M\&A to a certain extent.

\section{Theoretical Analysis}

\subsection{Analysis of the Influence of Management Characteristics on the Performance of Overseas M\&A}

The management of a company is the leading team responsible for the formulation and implementation of the overall strategy of the company, which includes the senior management personnel such as the chairman, director, supervisor, general manager, deputy general manager, chief financial officer and secretary of the board of directors. Enterprise performance is a comprehensive reflection of corporate strategy execution and business management. Management usually affects the performance of the company to a certain extent. Overseas M\&A is a major transaction that optimizes resource allocation and achieves strategic goals. It is a strategic implementation tool led by management. Due to different management styles and management capabilities, management may make different overseas M\&A decisions, which may lead to differences in M\&A performance. The management characteristics reflect the statistical status of management team members in terms of age, education level, professional background and overseas experience, which are important factors influencing management styles and management abilities. As the ages of those members are increasing, the cognitive and physical functions of the management are declining. This change results in a decline of their learning and innovation abilities. They become more conservative and slow-paced in the corporate management. The level of management education affects the management information processing capability. The management with high academic qualifications, for example, is better at handling information such as market and technology updates, and better able to effectively formulate or reformulate mergers and acquisitions practice patterns as well as promote technological innovation. Management with a professional technical background is able to pay more attention to innovation of enterprise technology, and is more capable of leading the company to fruitful technological innovation. The managers who have studied or worked abroad, who have advanced foreign management concepts and management practices, have a better understanding of the international market situation; accordingly, that type of managers pay more attention to the changing movements and trends in the development of international enterprises, and can more effectively adopt the international expansion strategies and absorb state-of-the-art foreign technology patterns. 


\subsection{M\&A Performance Evaluation based on the M\&A Motivational Factors}

From a management perspective, performance is the result of organizational expectations. Expectation comes from demand, and motivation is the specific manifestation of demand, so performance can be understood as a certain degree of motivation. Overseas mergers and acquisitions are a high-risk investment behavior. Only when driven by strong and clear motives or motivational factors will companies choose to engage in overseas mergers and acquisitions. The realization of M\&A motives is the result of the realization of overseas M\&A expectations. Through the measurement of the degree of realization of specific M\&A motives or motivational factors, the performance of overseas M\&A can be effectively evaluated.

\section{Review of the Case Enterprises Overseas M\&A}

Sany and Liugong are listed companies in China's machinery manufacturing industry. Both companies announced overseas M\&A transactions in 2012, which they had never done before. Besides the same year of M\&A announcement, the two companies have similarities in their respective industries, which include numbers of M\&A transactions. The comparability of the cases is relatively high. Therefore, the two companies were selected for a comparative case study.

\subsection{Sany's Acquisition of Putzmeister, Germany}

Sany Heavy Industry Co., Ltd., herein referred to as Sany was founded in 1994 by Sany Group and listed on the Shanghai Stock Exchange on July 3, 2003 (under stock code: 600031). The company has a registered capital of 7.78 billion yuan. It is a private enterprise, which belongs to the construction machinery industry. Its main business involves research and development, manufacturing and sales of construction machinery. The company is the largest construction machinery manufacturer in China and the fifth largest in the world, and the world's largest manufacturer of concrete machinery. Founded in 1958, Putzmeister is one of the world's best-known construction machinery manufacturers. Its products are known as the world's first brand of concrete machinery. On January 20, 2011, Putzmeister sought M\&A trading intentions from five Chinese companies, including Sany Heavy Industry. On January 30, 2012, Sany Heavy Industry announced that it would acquire a 100\% stake in Putzmeister, a decision jointly made with CITIC Fund. Among them, Sany Heavy Industry acquired 90\% through cash payment, and the purchase price was 324 million euros, equivalent to RMB 2.654 billion. CITIC Fund acquired 10\%. Three months later, the two companies completed the equity delivery and jointly announced the successful merger. On July 1, 2013, Sany Heavy Industry acquired the remaining 10\% stake in Putzmeister and completed a 100\% holding.

\subsection{Liugong's Acquisition of the Engineering Machinery Division of HSW Company.}

Guangxi Liugong Machinery Co., Ltd. (hereinafter referred to as Liugong) is one of the core enterprises of Liugong Group. It was founded by Liugong Group in 1993 and listed on the Shenzhen Stock Exchange (under stock code: 000528). Liugong's company has a registered capital of 1.125 billion yuan. It is a state-owned enterprise, which belongs to the construction machinery industry. Its main business is the productions and sales of construction machinery and accessories. Liugong is a leading company in China's construction machinery industry and the world's largest loader manufacturer. Founded in Poland in 1937, HSW (Huta Stalowa Wola) is the largest construction machinery manufacturer in Central and Eastern Europe and one of the six manufacturers of complete bulldozer production lines worldwide. On January 31, 2012, Liugong and Poland's HSW reached an acquisition agreement. Liugong acquired a $100 \%$ stake in the engineering machinery division of the Polish HSW company and its whollyowned subsidiary, Resta, for 170 million zlotys (about 335 million yuan).

\section{Analysis of the Motivational Factors for the Overseas M\&A}

The motivations for overseas M\&A of enterprises generally include four aspects: resource drivers, technology drivers, market drivers and brand drivers. Sany and Liugong belong to the construction machinery manufacturing industry. Therefore, their motivation for overseas mergers and acquisitions is mainly focused on the pursuit of technological innovation, expansion of the international market and enhancement of brand competitiveness.

\subsection{Product Technology Innovation}

The core product of enterprises of engineering machinery manufacturing is mechanical equipment. Equipment performance is one of the key factors determining the competitiveness of the enterprises. Good production technology and continuous technological innovation ability are effective guarantees for the excellent performance of enterprises. The innovation of technology has the characteristics of high cost, far-reaching longevity and high risk. However, enterprise can quickly acquire advanced foreign technology through overseas mergers and acquisitions. 
One of the motivational factors that drove Sany to acquire Putzmeister, the first-line brand in the global concrete machinery market, is to deepen the cooperation of concrete machinery technology between the two companies and enhance Sany's leading position in concrete machinery manufacturing technology. In its turn, one of Liugong's motives for acquisition is to use HSW's complete bulldozer production line manufacturing capacity to cultivate its own bulldozer business while consolidating its ability to provide complete solutions for construction machinery.

\subsection{International Market Expansion}

Expanding into the international market is an effective way for companies to become bigger and stronger, but the establishment of an international marketing network is not an easy task, and different regional markets may have some differences in product demand and marketing opportunities. In fact, overseas M\&A companies can directly use the marketing network resources of the target companies abroad, and can effectively compare the differences in product demand between different markets and strategically open up the international market. In the case of Sany and Liugong, after decades of development, the companies have become the leading enterprises in the domestic construction machinery manufacturing industry, but the international business sales had been performing poorly. From 2009 to 2011 , Sanyand Liugong's average international business revenue accounted for only $7.09 \%$ and $9.67 \%$ respectively. Both companies urgently need to expand into the international market and enhance their international sales capabilities.

\subsection{Brand Value Improvement}

Overseas M\&A companies can combine the value advantages of the two brands through technical, marketing and financial synergies to enhance their brand awareness and competitiveness in both domestic and international markets. Through the acquisition of overseas high-quality brand enterprises, not only do Sany and Liugong acquire advanced foreign technology and expand international market business, but also achieve strong alliance among high-quality brands. While deepening the domestic recognition of their brands, the two companies have also enhanced the international influence of the brand, and the brand effect has been greatly reinforced.

\section{Measurement and Comparative Analysis of the Enterprises Overseas M\&A Performance}

From the case companies, the main motives of overseas M\&A are divided into three aspects. The measurement of M\&A performance focuses on the realization of the three major motives.

\subsection{Performance Measurement and Comparative Analysis of Technological Innovation Abilities}

The most appropriate indicator for measuring corporate innovation is the number of patents in the enterprise (Pakes, 1980). A patent is a technological innovation that is recognized and protected by law, and is one of the effective indicators that reflect the performance of a company in terms of technological innovation. The cumulative number of Sany's patents continued to increase between 2010 and 2017, and the increment number recorded between 2012 and 2013 was significantly larger than that of the previous years (as seen in Table 1). Through the rapid accumulation between 2012 and 2013, Sany's patents ranked first in the domestic industry, and it also shows that the technological innovation performance brought by overseas M\&A transactions is obvious. The cumulative number of Liugong patents continued to grow throughout the period, but the growth was relatively flat, and there were no obvious rapid growth stages. Thus, the performance of overseas M\&A regarding technology innovation was not sustainable.

Table 1. The Two Companies' Annual Patent by Increments, 2010-2017

\begin{tabular}{lcccccccc}
\hline & 2010 & 2011 & 2012 & 2013 & 2014 & 2015 & 2016 & 2017 \\
\hline Sany Heavy Industry & 302 & 441 & 936 & 773 & 148 & 182 & 57 & 6 \\
Liugong & 42 & 94 & 123 & 151 & 196 & 170 & 217 & 353 \\
\hline
\end{tabular}

Source: Wind database

In addition, the number of patent applications per year is also one of the evaluation indicators reflecting the innovation ability of enterprises. Patents are divided into three types in China: inventions, utility models and designs. Among them, inventions refer to new technical solutions proposed for products, methods or improvements, and are the most technologically innovative types of patents. Considering the invention that was ultimately authorized by law, the number of invention patent applications filed by Sany in 2012 was 1,045, reaching a peak, showing significant overseas M\&A technology innovation performance (Table 2). For the invention application, Liugong has generally increased slowly, but it has not increased significantly after the merger. Therefore, the performance of overseas M\&A technology innovation is not obvious enough. 
Table 2: Annual Invention Applications, 2010-2017

\begin{tabular}{lllllllll}
\hline & 2010 & 2011 & 2012 & 2013 & 2014 & 2015 & 2016 & 2017 \\
\hline Sany Heavy Industry & 271 & 423 & 751 & 380 & 77 & 101 & 63 & 3 \\
Liugong & 14 & 27 & 51 & 66 & 112 & 47 & 34 & 5 \\
\hline
\end{tabular}

Source: Rain Pat Patent Search Database

6.2 Measurement and Comparative Analysis of Performance in International Expansion

The expansion of the international market of enterprises is essentially the expansion of the product market, and the performance of international expansion can be reflected by the overseas sales of products. Both case companies achieved an increase in overseas sales revenue in 2012, but the gap between them also increased significantly (Table 3 ). In addition, before 2012, Sany's overseas sales accounted for a lower proportion than those of Liugong, but the situation was the reverse in 2013 after the merger and the company continued to maintain its advantage thereafter. Therefore, Sany's performance seen through the expansion of overseas M\&A is significantly better than that that of Liugong.

Table 3: Annual Overseas Sales Revenue, 2010-2017

\begin{tabular}{l|llll}
\hline & \multicolumn{2}{|l}{ Sany Heavy Industry } & \multicolumn{2}{l}{ Liugong } \\
\cline { 2 - 5 } & Value (bil RMB) & Proportion & Value (bil RMB) & Proportion \\
\hline 2010 & 2.13 & $6.28 \%$ & 1.31 & $8.55 \%$ \\
2011 & 3.43 & $6.75 \%$ & 2.12 & $11.84 \%$ \\
2012 & 8.74 & $18.66 \%$ & 3.15 & $24.97 \%$ \\
2013 & 10.87 & $29.13 \%$ & 2.44 & $19.39 \%$ \\
2014 & 9.82 & $32.25 \%$ & 2.52 & $24.51 \%$ \\
2015 & 10.03 & $42.39 \%$ & 2.10 & $31.51 \%$ \\
2016 & 9.29 & $39.89 \%$ & 2.02 & $28.79 \%$ \\
2017 & 11.62 & $30.31 \%$ & 2.44 & $21.63 \%$ \\
\hline
\end{tabular}

Source: Wind database

\subsection{Measurement and Comparative Analysis of Performance in Brand Improvement}

A brand effect is influenced by many factors such as brand awareness and brand competitiveness, and it ultimately reflects brand recognition and consumption promotion, which can be reflected by brand value. From 2010 to 2017, the brand value of the two companies continued to rise, but the upward trend was relatively stable, and the two companies did not show significant differences in that regard (Figure 1).

Figure 1: Annual brand value, 2010-2017

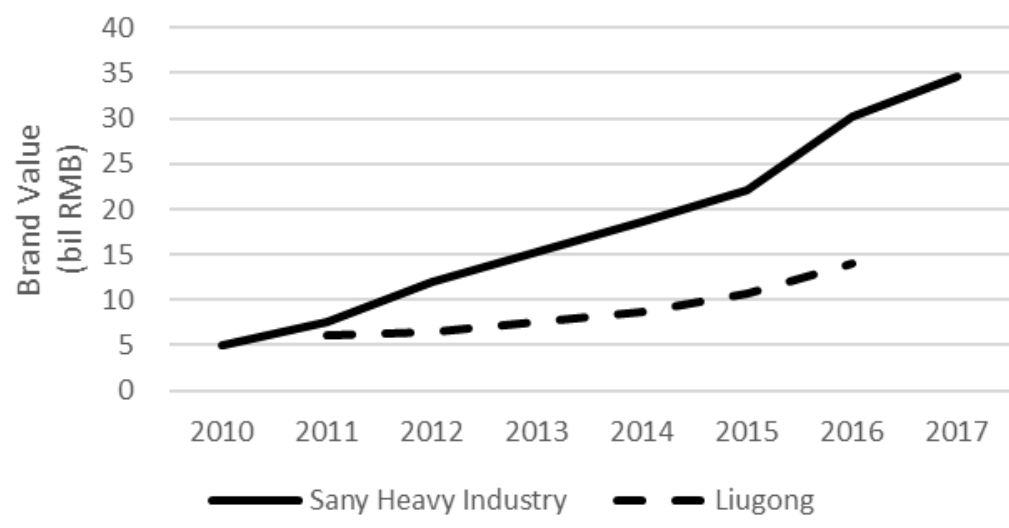

Source: Analysis Report of China’s 500 Most Valuable Brands by World Brand Lab 


\section{Analysis of the Causes of the Performance Differences in Reference to Management Characteristics.}

Management is the leader and executor of overseas mergers and acquisitions. Different characteristics are conducive to different management styles and capabilities, which have an impact on M\&A transactions and their performance. The performance of the overseas M\&A of the two case companies differs significantly in terms of technological innovation and international expansion. This paper analyzes the reasons for the differences from the perspective of management characteristics.

\subsection{The Causes of the Performance Differences in Technology Innovation}

Regarding the age of the management team members, the case companies were divided between the 40s and 80sin their distribution, and their births were mainly concentrated in the 1950s and 1960s. Therefore, the management personnel born in the 1940s and 1950s were classified as senior management personnel, whereas those of 1960s and 1980s were classified as young managers. Among Liugong's management, the proportion of senior management personnel exceeds one third, which is 10 percentage points more than that of Sany, which probably make the management style of the company become relatively conservative. That, in turn, can affect the achievement of the company's technological innovation performance (Table 4). In terms of the management education, a $\mathrm{Ph} . \mathrm{D}$, for example, requires a person to have the ability to produce original results, which is supposed to be the most innovative degree. Liugong's management doctors or Ph.D holder's ratio is less numerous than that of Sany, which may affect the efficiency of enterprise technology innovation. In reference to professional or technical background, senior engineers have rich experience in production and technical management, and they can solve important technical problems. They play an important role in the technological innovation of the construction machinery industry. The proportion of senior engineers in the management team of Sany is nearly 9 percentage points higher than that of Liugong, which may prompt enterprises to pay more attention to technological innovation and improve the efficiency of such innovation. As regards international background, management with an overseas experience pays more attention to the cutting-edge technologies and development practices in the international market, which can help companies more efficiently absorb advanced and state-of-the-art technology patterns from foreign companies. The proportion of Sany's management with an overseas experience exceeds Liugong's by $25 \%$, which may be one of the reasons why its overseas M\&A technology innovation performance is significantly better than that of Liugong.

Table 4: Management Characteristics of the Two Cases, 2009-2012

\begin{tabular}{|c|c|c|c|c|c|c|c|}
\hline & $\begin{array}{l}\text { Proportion } \\
\text { seniors }\end{array}$ & $\begin{array}{l}\text { of Proportion } \\
\text { doctors }\end{array}$ & of & $\begin{array}{l}\text { Proportion of } \\
\text { senior engineers }\end{array}$ & $\begin{array}{l}\text { Proportion } \\
\text { international } \\
\text { background } \\
\text { personnel }\end{array}$ & $\begin{array}{l}\text { of } \\
\text { of }\end{array}$ & $\begin{array}{l}\text { Average } \\
\text { number of } \\
\text { management } \\
\text { personnel }\end{array}$ \\
\hline Sany & $24.55 \%$ & $15.45 \%$ & & $22.73 \%$ & $33.64 \%$ & & 28 \\
\hline Liugong & $34.88 \%$ & $9.30 \%$ & & $13.95 \%$ & $8.41 \%$ & & 22 \\
\hline
\end{tabular}

\subsection{The Causes of the Difference of Performance in International Expansion}

Managements with an international experience are more familiar with overseas markets and can more effectively help companies to carry out overseas expansion. Except for one independent director, who has worked as a researcher at an overseas university, the rest of Sany's management have studied overseas. Liugong's proportion of management with overseas experience is only $8.41 \%$, all with international background due to overseas studies and corporate management. Liugong's management has a relatively small proportion of overseas experience, which may affect its performance in the company's overseas market expansion.

\subsection{The Causes of Difference in Brand Promotion Performance}

Brand value can to be achieved through consumer brand recognition promoting consumption, for that aspect, it is an abstract and comprehensive value manifestation, which may not be able to quickly and significantly increase through M\&A. Therefore, the performance difference between the two case companies in terms of brand value improvement is not obvious. This study does not cover the analysis of whether management characteristics affect the brand's performance in overseas mergers and acquisitions. 


\section{Research Conclusions, Implications and Limitations}

On the basis of theoretical analysis, this article uses case comparison method to examine the motivational factors of overseas M\&A of Sany Heavy Industry Co. Ltd and Guangxi Liugong Machinery Co., Ltd., and then measure the performance of their overseas M\&A. In other words, this study looks for reasons that influence the performance of overseas M\&A from the perspective of management characteristics. The results made it clear that, since the year 2012, the time the two case companies embarked on overseas M\&A, they have achieved development in product technology innovation, international market expansion and brand value enhancement. However, Sany's overseas M\&A performance is found to be more significant, especially in terms of product technology innovation and international market expansion than its counterpart, Liugong. From the management characteristics analysis, Sany has a small proportion of senior managers of older ages, but with a high proportion of employees with Ph.D degrees and senior engineers among its management staff, which may be the reason why its technical innovation performance was conspicuous. Also, a higher proportion of executives with overseas experience may explain Sany's more successful performance in the international expansion.

This paper outlines some significant guidance on how to improve the performance of overseas M\&A and optimize the management structure. From the present findings, it is realized that, on the one hand, in the process of building management, reducing the proportion of senior managers and increasing the proportion of $\mathrm{Ph} . \mathrm{D}$ holders and senior engineers help companies choose overseas M\&A goals and efficiently integrate core technologies, which can quickly achieve certain level of corporate technology innovation performance. On the other hand, companies trying to expand into the international market through overseas M\&A should pay attention to the overseas background or experience of management. The international background of management can be improved by sending internal management personnel to study abroad and/or recruiting senior management with overseas experience.

Like many research works in existence, this paper is not immune to limitations. The article, for example, fails to answer the question of whether management characteristics affect the performance of overseas M\&A from the perspective of brand promotion. Future research may attempt to analyze this area from other research paths. In addition, the paper only studies the impact of management characteristics on overseas M\&A by way of case comparison. Future research could provide empirical evidence for this impact through large sample empirical studies.

\section{References}

Feng, Yinbo; Liu,Yujia. (2016). "Financial Performance Analysis of Chinese Private Enterprises' Cross-industry Overseas M\&A: A Case Study of Fosun M \& A FolliFolli.” Modernization of Management, (03): 73-75.

GuoRui, Tao Lan, Wang Tao, Zhou Nan. (2012). "Research on Brand Strategy of National Brands after Cross-border Mergers and Acquisitions__ _ A Perspective of Weak Brands." Nankai Business Review, (03): 42-50.

Hu Haiqing, Wu Tian, Zhang Lang, Zhang Dan. (2016). "The Study on the Performance of Overseas Merger and Acquisition Based on Synergy Effect: A Case Study of Geely M\&A Volvo." Journal of Management Case Studies, (06): 531-549.

Liu Bai, Liang Chao. (2017). "The Board's Overconfidence and the International M\&A Performance." Business Management Journal, (12): 73-88.

Liu Qing, Tao Pan, Hong Junjie. (2017). "The Motivation for China's Overseas M\&As: The Extensive Margin and the Intensive Margin.” Economic Research Journal, 52(01): 28-43.

Li Zhengdong (2010). "The Impact of Managers' Characteristics on the Internationalized Performance of Enterprises: An Empirical Test Based on the Data from Chinese State-controlled Manufacturing Listed Companies." Economic Survey, (03): 57-60.

Nadolska, Anna; Barkema, Harry G. (2014). "Good learners: How top management teams affect the success and frequency of acquisitions.” Strategic Management Journal, 35(10): 1483-1507.

Wu Xianming, Su Zhiwen. (2014). "Cross-border M\&A as a lever for technology catch-up: a perspective of dynamic capabilities." Management World, (04): 146-164.

Wu Yingyu, Chen Song (2017). "Will cross-border mergers and acquisitions influence innovation performance of emerging market firms? —— The effect of TMT international experience.” Studies in Science of Science, (09): 1378-1385.

Yin Aizhen, Ma Xiaoli, Yu Peng. (2018). "Performance Evaluation of M\&A Based on M\&A Motives." Finance and Accounting Monthly, (11): 107-114.

Yan Daying (2016). "International Experience, Cultural Distance and the Performance of Chinese Enterprises' Overseas M\&A.”Economic Review, (01): 83-92. 
Yang Xiaojia, Chen Shou. (2005). "A Matrix Model of M\&A Performance Evaluation for Listed Companies." The Theory and Practice of Finance and Economics, (02): 64-68.

Yuan Zeming, GuJiayi, Fu Yuyuan. (2018). "Research on Performance Evaluation of "Small mergers big 'Overseas M\&A Model—_ A Case Study of Geely Group." Friends of Accounting, (16): 60-65.

Zhou Shaoni, Wen Haitao. (2013). "Performance Evaluation of M\&A Based on Industrial Evolution and Motives." Accounting Research, (10): 75-82+97. 